\title{
A Call for Truth in the Fashion Pages: What Global Trend in Advertising Regulation Means for U.S. Beauty and Fashion Advertisers
}

Ashley O'Neil

Indiana University Maurer School of Law, aaoneil@indiana.edu

Follow this and additional works at: https://www.repository.law.indiana.edu/ijgls

Part of the Administrative Law Commons, Advertising and Promotion Management Commons, Commercial Law Commons, First Amendment Commons, International Law Commons, and the Marketing Law Commons

\section{Recommended Citation}

O'Neil, Ashley (2014) "A Call for Truth in the Fashion Pages: What Global Trend in Advertising Regulation Means for U.S. Beauty and Fashion Advertisers," Indiana Journal of Global Legal Studies: Vol. 21 : Iss. 2 , Article 9.

Available at: https://www.repository.law.indiana.edu/ijgls/vol21/iss2/9

This Note is brought to you for free and open access by the Law School Journals at Digital Repository @ Maurer Law. It has been accepted for inclusion in Indiana Journal of Global Legal Studies by an authorized editor of Digital Repository@Maurer Law. For more information, please contactrvaughan@indiana.edu.

\section{$\Psi$}

JEROME HALL LAW LIBRARY

INDIANA UNIVERSITY

Maurer School of Law
Bloomineton 


\title{
A Call for Truth in the Fashion Pages: What the Global Trend in Advertising Regulation Means for U.S. Beauty and Fashion Advertisers
}

\author{
ASHLEY O'NEIL *
}

\begin{abstract}
The advertising industry serves an important purpose in our society by acting as the main source of information for consumers about products. Global advertisement spending reaches into the hundreds of billions of dollars annually. Because advertising plays such a large role in the economy, regulators across the globe have increasingly sought to promote truth in advertising. As a result, advertising regulation has exploded in the recent decades. Recently, the beauty and fashion industries have come under fire from advertising regulatory bodies, most notably in Europe, for misleading and offensive advertising practices. Regulators and interest groups are concerned by the unrealistic portrayals of models in these advertisements and the effects these portrayals have on consumers, young women in particular. While the call for heavier regulation of beauty and fashion advertising has picked up steam in countries across the world, the United States has been more reluctant to regulate. The protection of commercial speech under the First Amendment makes it more difficult to enact such regulations in the United States than in other countries that have more regulatory-friendly cultures. Despite the hesitation by U.S. regulators to police advertising practices in the beauty and fashion industries, U.S. advertisers must take note of the global advertising trend and alter their advertising practices to conform to the growing cultural concern about misleading advertising. Taking such steps is necessary for U.S. companies to maintain their foothold with consumers in foreign markets.
\end{abstract}

* Executive Articles Editor, Indiana Journal of Global Legal Studies; J.D. Candidate, 2014, Indiana University Maurer School of Law; B.A., 2011, Indiana University-Bloomington.

Indiana Journal of Global Legal Studies Vol. 21 \#2 (Summer 2014)

(C) Indiana University Maurer School of Law 


\section{INTRODUCTION}

Advertising exists everywhere in our world today. In the United States, a person may be exposed from anywhere between 300 to 1,500 advertisements per day and over 100,000 each year. ${ }^{1}$ In 2012 , U.S. companies spent $\$ 140$ billion dollars on domestic and global advertising across television, print, and online platforms. ${ }^{2}$ Billions of that money is spent by the beauty and fashion industries. Kantar Media, an advertising strategy firm, reported that $\$ 6.8$ billion was spent on advertising for personal care products in $2012 .^{3}$ The beauty industry includes make-up, skin and hair care products, perfumes, cosmetic surgery, health clubs, and weight loss products. ${ }^{4}$ These products form a $\$ 160$ billion global industry that feeds the world's desire to be young and beautiful. ${ }^{5}$

The beauty and fashion industries sell consumers, mostly women, products to make them thinner, younger, and more attractive. Claims in beauty and fashion advertisements about product effectiveness have become more extravagant, ${ }^{6}$ while, at the same time, the models used in these advertisements have become slimmer. ${ }^{7}$ This suggests that beauty and fashion advertisements have been selling an idea of beauty that has become less in tune with reality over time. These unrealistic portrayals have led to increasing concern about the effects of advertisements on body image and self-esteem, particularly in the wake of growing numbers of eating disorders among young girls and women.

1. W. JAMEs PotTER, MEdia Literacy 221 (4th ed. 2008)

2. Press Release, Kantar Media, Kantar Media Reports U.S. Advertising Expenditures Increased 3 Percent in 2012 (Mar. 11, 2013), available at http://kantarmedia.us/press/kantar-media-reports-us-advertising-expenditures-increased3-percent-2012.

3. Id.

4. Pots of Promise: An Industry Driven by Sexual Instinct Will Always Thrive, ECONOMIST, May 22, 2003, available at http://www.economist.com/node/1795852.

5. Id.

6. See id.

7. See Madeline Jones, Plus Size Bodies, What Is Wrong With Them Anyway?, PLUS MODEL MAG. (Jan. 8, 2012), http://www.plus-model-mag.com/2012/01/plus-size-bodieswhat-is-wrong-with-them-anyway/ (discussing the shrinking size of models over the past twenty years); Katharine Gammon, Infoporn: Today's Playmates Are More Like Anime Figures Than Real Humans, WIRED (Feb. 19, 2009, 6:00 PM), http://archive.wired.com/ special_multimedia/2009/st_infoporn_1702 (showing that as the body mass index (BMI) of average U.S. young women from the 1960 s to the 2000 s has increased, the BMI of Playboy Playmates over the same period has shrunk). 
The result of these concerns has been attempts to increase regulation of advertising practices, most notably in the United Kingdom and France. Legislators in both countries have sought to pass legislation in recent years to limit certain practices, such as digital manipulation of photographs in advertisements that can mislead consumers about product performance. ${ }^{8}$ Self-regulatory bodies in both countries have pushed to ban cosmetic advertisements for misleading consumers in this way. A similar call for more regulation of the advertising industry has developed in the United States, although U.S. regulators have been slower to act than their European counterparts, in part because of the United States' strong commitment to free speech protection.

This note will examine the current state of advertising regulation in the United Kingdom, France, and the United States, with a focus on regulation of the beauty and fashion industries. I will also look at what the global trends in advertising regulation mean for U.S. businesses within these industries. Part I of the note will discuss the systems of regulation within the three countries, as well as current and proposed legislation that may affect beauty and fashion advertising. Part II of the note will discuss recent advertising bans in the three countries as a means of showing how the United States has been slower than the United Kingdom and France in addressing misleading and inappropriate advertising practices. In Part III, I will argue that the global nature of the world economy will require U.S. beauty and fashion advertisers to be aware of foreign advertising regulation and to conform their practices to stricter international advertising standards. It is in the best economic interest of U.S companies to self-regulate their advertising practices in this way if they hope to maintain consumers and earn revenue in foreign markets.

\section{REGULATION OF ADVERTISING}

Every country has its own set of regulations concerning what is proper for advertisements. The United States is more lax than other countries in its regulation of advertising. This is consistent with the great protection that the United States affords freedom of speech. Regulation of advertising in the United States is controlled by the commercial free speech doctrine. Other countries, such as the United Kingdom, have been much more willing to impose restrictions on the advertising industry. The United Kingdom relies on a system of self-

8. Eric Pfanner, A Move to Curb Digitally Altered Photos in Ads, N.Y. Times, Sept. 28, 2009, at B5, available at http://www.nytimes.com/2009/09/28/business/media/ 28brush.html?_r=1\&adxnnl=1\&adxnnlx=1356546737-a/++DOdbSZgG1BcxCygsyQ\&. 
regulation by a nongovernment organization, the Advertising Standards Authority (ASA), to regulate both broadcast and nonbroadcast advertising and marketing. ${ }^{9}$ France also depends on a system of selfregulation similar to the ASA. In the United Kingdom and other foreign countries, a recent movement has pushed to increase regulation of misleading advertising, particularly in the beauty and fashion industries. This trend toward stricter regulation of misleading advertisements has become a focus of advocacy groups and legislatures across the world. So far, the United States has been reluctant to join in this trend.

\section{A. Self-Regulation and Legislation in the United Kingdom}

The United Kingdom relies on a system of self-regulation of the advertising industry that is run by a nongovernmental regulatory body known as the Advertising Standards Authority. ${ }^{10}$ Regulation by the ASA is based on the CAP Code (Code), a set of rules developed by the Committee of Advertising Practice (CAP). ${ }^{11}$ CAP has promulgated two different codes, one for broadcast advertising and another for nonbroadcast advertising, sales promotion, and direct marketing. ${ }^{12} \mathrm{CAP}$ is made up of member organizations in the advertising, marketing, and sales businesses, as well as media publishers that have agreed to follow the advertising codes. ${ }^{13}$ While the Code is not law, compliance with the Code is often synonymous with compliance with the law. ${ }^{14}$ The government and the courts recognize this self-regulatory system as an "established means" to protect consumers from false and misleading advertising. ${ }^{15}$ This system acts as the frontline for advertising regulation and often is the most efficient way to resolve issues about advertising content. ${ }^{16}$

As the main body of the self-regulatory system, the ASA functions as the investigative and promotional arm. Its tasks include the investigation of complaints, research of current trends and problem

9. About ASA, ASA: ADVERTISING STANDARDS AUTHORITY, http://www.asa.org.uk/AboutASA.aspx (last visited Apr. 21, 2014).

10. Comm. of Adver. Practice, The CAP Code: The UK Code of Non-broadcast advertising, Sales Promotion and Direct Marketing 3 (12th ed. 2010), available at http://www.cap.org.uk/Advertising-Codes/ /media/Files/CAP/Codes\%20CAP\%20pdf/ CAP\%20Code\%200712.ashx.
11. Id.
12. Id.
13. Id.
14. Id.
15. Id. at 105 .
16. See id. at 103. 
areas within advertising, and the "ensur[ance] that the system operates in the public interest." 17 The ASA is made up of a twelve-member council of individuals who are independent of both the government and the advertising industry. ${ }^{18}$ The ASA also works to keep involved with current advertising trends. To this end, the ASA maintains an "extensive media presence," through which it seeks to inform the public and the advertising industry of its policies and focuses of concern. ${ }^{19}$

When the ASA determines that an advertisement does not comply with the Code, the marketer responsible for the advertisement is required to amend or withdraw it.20 Failure to do so may result in sanctions, although the ASA's main priority is in ensuring the amendment or removal of the noncompliant ad. ${ }^{21}$ Essential to the ASA's ability to promote compliance is its use of adverse publicity by publishing its rulings on the ASA website and other media outlets. ${ }^{22}$ Another form of sanction for noncompliant advertisers may be the denial of media space. Advertisement alerts to CAP members warn the media and other publishers not to run advertisements by noncompliant marketers. ${ }^{23}$ Other sanctions for repeat offenders may include the denial of trading privileges and pre-publication vetting of repeat offenders. ${ }^{24} \mathrm{~A}$ final sanction for failure to comply with an ASA ruling may be a referral to the Office of Fair Trading (OFT) for legal action in the courts. ${ }^{25}$

\section{The Code}

The UK Code of Non-broadcast Advertising, Sales Promotion and Direct Marketing applies to all print advertisements-including those in magazines, newspapers, and catalogues-and electronic materials such as e-mails, online advertisements, and video. ${ }^{26}$ The basic principle underlying the Code is that "all marketing communications . . . should be legal, decent, honest and truthful. [They] should be prepared with a sense of responsibility to consumers and society and should reflect the spirit, not merely the letter, of the Code."27

\footnotetext{
17. Id. at 98 .

18. Id.

19. Id.

20. Id. at 104.

21. Id.

22. Id.

23. Id. at 105.

24. Id.

25. Id.

26. Id. at 6 .

27. Id. at 12 .
} 
One major section of the Code deals with misleading advertising. The ASA regulates potentially misleading advertisements and marketing communications based on their potential effects on consumers, rather than the intent of the advertiser. ${ }^{28}$ Rule 3.1 states that advertisements "must not materially mislead or be likely to do so."29 However, "puffery" and obvious exaggerations that most consumers would not take literally are usually allowed..$^{30}$ The Code forbids advertisements that mislead consumers by leaving out or concealing material information needed by consumers to make informed decisions; ${ }^{31}$ for example, omitting the identity of the advertiser, or implying that opinions are objective claims of fact. ${ }^{32}$ Furthermore, Rules 3.8 and 3.11 prohibit advertisers from exaggerating the value, performance, or usefulness of the product. ${ }^{33}$

Another founding principle of the Code is that advertisers "should take account of the prevailing standards in society and the context in which [the] communication is likely to appear to minimise the risk of causing harm or serious or widespread offence." ${ }^{34}$ Rule 4.1 does make clear, however, that just because an advertisement is distasteful or might offend some people, does not mean that it is in violation of the Code. ${ }^{35}$

The Code contains a special section to address advertising in the medical, health, and beauty industries. The Code requires claims about a product's ability to deal with medical treatments or ailments, including those for cosmetic products, to be backed by evidence. ${ }^{36}$ Advertisements for cosmetic products may not include unsubstantiated claims to "cure" or rejuvenate, but claims to relieve certain symptoms might be allowed if they can be substantiated. ${ }^{37}$ Rule 13.3 prohibits the targeting of people under eighteen years of age for weight-loss products, either directly or through appealing content. ${ }^{38}$ Additionally, such

28. $I d$. at 18.

29. $I d$.

30. $I d$.

31. See id. Rules 3.3 and 3.4 address what counts as material information and how the absence of that information can be misleading.

32. Id. at 18-19.

33. Id. at 19.

34. Id. at 28. The Code contains an entire section devoted to preventing advertising that could be harmful to consumers, placing particular emphasis on ads that could cause offense on such grounds as race, religion, sexual orientation, gender, age, or disability. See id.

35. Id.

36. See id. at 58. Rule 12.1 distinguishes between true medicinal claims and secondary claims for cossnetic products. Id.

37. Id. au 59 .

38. Id. at 64 . 
advertisements "must not suggest that being underweight is desirable or acceptable." 39 The Code makes clear that advertisements and other marketing communications that deal with weight and weight-control should be subject to a "high level of scrutiny." 40

While advertisements that originate outside the United Kingdom but directly target British consumers are not officially subject to the jurisdiction of the Code and the ASA, where the foreign jurisdiction does not have a similar self-regulatory complaint system, the ASA is authorized to take some action. ${ }^{41}$ Because the British media is a part of CAP, however, foreign advertisers are bound to the Code if they want their advertisements to appear in British magazines and other print media.

\section{The Consumer Protection from Unfair Trading Regulations 2008}

While the Code is the main enforcement mechanism for advertising regulation, the advertising industry is also subject to other legislation. The Code works in conjunction with a major piece of secondary legislation to regulate potentially misleading advertising: the Consumer Protection from Unfair Trading Regulations 2008 (CPRs). ${ }^{42}$ The ASA considers the CPRs when making rulings under the Code.

The CPRs lay out prohibitions against unfair, misleading, and aggressive advertising that are similar to those in the Code. Part two of regulation five of the CPRs addresses the prohibitions on misleading advertising. ${ }^{43}$ Under regulation five, it is a violation for an advertisement to contain false information or to deceive the average consumer on matters concerning the nature and characteristics of the product or the risks to the consumer in using the product if such a false claim or deception "is likely to cause the average consumer to take a transactional decision he would not have taken otherwise." 44 Paragraph three of regulation five also makes it a potential violation of the CPRs for an advertiser to fail to comply with a code to which the advertiser has made a commitment to comply as part of its commercial practice. ${ }^{45}$ This paragraph provides cohesion between the CPRs and the Code.

39. Id.

40. Id.

41. Id. at 6-7.

42. Id. at 113 .

43. Consumer Protection from Unfair Trading Regulations, 2008, S.I. 2008/1277, pt. 2, reg. 5 (U.K.).

44. Id. at reg. 5 , II 2,4 . Paragraph 4 provides a complete list of the information that must be accounted for truthfully and accurately in an advertisement.

45. See id. at reg. 5, \ 3. 


\section{New Proposed Legislation}

While the Code and the CPRs provide general prohibitions on false and misleading advertising, there has been a recent legislative focus in the United Kingdom on regulating digitally altered images in advertising, particularly in relation to models in beauty and fashion advertisements. The growing use of Photoshop in the advertising industry, and in the beauty and fashion industries in particular, has created concerns about the promotion of unrealistic expectations about body image and the effects those expectations have on consumers, most notably young girls.

In 2009, the Liberal Democratic Party adopted as part of its platform a proposal made by Liberal Democrat Jo Swinson that would require warning labels to be placed on all advertisements containing altered or manipulated images and photographs. ${ }^{46}$ The proposal would also ban all manipulated photographs in advertisements that target children under sixteen. ${ }^{47}$ Swinson argues that the use of digitally altered photographs of models in fashion and beauty advertisements leaves teenagers "feeling unhappy with themselves." 48 The warning system would give each advertisement containing altered images a rating from one to four, depending on the amount of retouching that was done, with a corresponding explanation of the changes that were made. ${ }^{49} \mathrm{~A}$ four on the rating scale would be used for images with significant enhancements, or what Swinson calls "digital cosmetic surgery," while a one might be warranted for enhancements to the lighting or background of the photo. ${ }^{50}$ It was Swinson's hope that, through the ASA and CAP, the advertisement industry would voluntarily adopt this rating practice rather than having it imposed on them through legislation. ${ }^{51}$ The push for warning labels on altered photos has been supported by some of Britain's leading psychologists and doctors, who put together a report for the ASA discussing the effects of media portrayals on body image. ${ }^{52}$

46. Pfanner, supra note 8 .

47. $I d$.

48. $I d$.

49. Id.

50. Id.

51. Id.

52. James Kirkup, Airbrushed Images Harming Girls and Boys, Experts Say, TELEGRAPH (Nov. 9, 2009, 12:23 PM), http://www.telegraph.co.uk/news/politics/ liberaldemocrats/6516537/Airbrushed- images-harming-girls-and-boys-experts-say.html. 
The self-regulatory system headed by the ASA has been described as the "most developed and effective self-regulatory system in the world." 53 Through the Code, the CPRs, and the recent call for heavier regulation on digitally altered advertising, British consumers, the advertising industry, and the government have shown a willingness to impose restrictions on advertising practices. The goal of these regulations is to protect consumers from the dangers of misleading advertising. Because of its well-developed regulatory system, the United Kingdom is one of the world leaders in promoting truthful advertising.

\section{B. Self-Regulation and Legislation in France}

France has a similar self-regulatory scheme as the United Kingdom. The Autorité de Régulation Professionnelle de la Publicité (ARPP) is an independent body that works to maintain a balance between creativity, advertiser freedom, and the responsibility to consumers. ${ }^{54}$ The ARPP consists of the Jury de Déontologique Publicitaire (JDP), which deals with consumer complaints about advertisements that may not be compliant with the rules, and the Conseil Paritaire de la Publicite (CPP), which drafts the rules. ${ }^{55}$ Like the British CAP, the CPP consists of advertisers and media organizations that, together, draft the code of standard practices for the industry. ${ }^{56}$ The ARPP Standards identify many different types of advertising and have specific rules for certain industries or products. The ARPP also has a general list of " 10 Golden Rules of Advertising Ethics" that prevent advertisers from misleading the consumer about a product and its results, trivializing harmful behaviors, and disrespecting the sensitivity and dignity of the public by use of harmful stereotypes or representations that would exploit the innocence of children. ${ }^{57}$

Beyond the general rules, the ARPP has developed specific rules for advertising of cosmetic products. The rules define a cosmetic product as "any substance or preparation intended to be put in contact with the different superficial parts of the human body . . . or with the teeth ... in

53. Jean J. Boddewyn, Global Perspectives on Advertising Self-Regulation 3 (1992).

54. Global Presentation, AUTORITÉ DE RÉGUlation PROFEsSiOnNELLE DE LA PUBLICITÉ, http://www.arpp-pub.org/Global-Presentation.html (last visited Apr. 21, 2014).

55. Id.

56. Id.

57. See The 10 Golden Rules of Advertising Ethics, AUTORItÉ DE RÉGULATION PROFESSIONNELLE DE LA PUBLICITÉ, http://www.arpp-pub.org/IMG/pdf/10_golden_rules.pdf (last visited Apr. 21, 2014). 
order to . . clean, perfume, modify their appearance . . . and/or protect or keep them in good condition." 58 These rules apply to advertising on any platform, whether it is in print, broadcast, or electronic form. ${ }^{59}$ Any claims made in cosmetic advertisements must be "truthful, clear, fair, objective and should not be likely to mislead."60 Claims about the product's performance should be substantiated with proof, usually through some sort of scientific test.61 Further, Rule 1/3. 2b/ states that when visual illustrations are used to show results of the product, the visual representation must be proportional and reflective of the actual performance of the product. ${ }^{62}$ Like the British Advertising Code, the French rules are very specific about advertisements concerning weight loss products. Rule $2 / 5 \mathrm{a} /$ prohibits the use of the words "[w]eight loss," or their equivalent, in advertising for cosmetic products; ${ }^{63}$ however, the word "slim" and its equivalents are allowed in reference to "improved aesthetic appearance." 64 The rules provide other restrictions on specific cosmetic products, including words and claims that are forbidden.

France has recently introduced legislation to require warning labels on advertisements containing digitally altered or retouched images. Valerie Boyer proposed a bill in 2009 to the National Assembly that would require warnings on altered photos used for editorials and in print advertisements. ${ }^{65}$ The bill also called for fines of $€ 37,500$, an equivalent of $\$ 55,000 .^{66}$ More than fifty other legislators supported Boyer's bill. ${ }^{67}$ The bill was introduced at a time when France was concerned about eating disorders among young women, and Boyer argued that the idealized beauty created by retouched images in advertising was "creating parallel worlds," where the beautiful, slim, nearly perfect models found in advertisements do not mesh with the imperfect reality of normal life. ${ }^{68}$ By creating unrealistic expectations about what is beautiful, Boyer believes that these advertisements are

58. Autorité de RÉgulation Professionnelle de la Publicité, Cosmetic PRoDUCTS 1 (2009) (Fr.), available at http://www.arpp-pub.org/TMG/pdf/Cosmetic_Products2.pdf (borrowing the definition for cosmetics from article L. 5131-1 of the French health code).

59. Id.

60. Id.

61. Id. at 2 .

62. Id. at 3 .

63. Id. at 4 .

64. Id.

65. Pfanner, supra note 8.

66. Id.

67. Bruce Crumley, France May Put Warning Labels on Airbrushed Photos, Time (Oct.

5, 2009), http://www.time.com/time/world/article/0,8599,1927227,00.html.

68. Id. 
misleading to the public. ${ }^{69}$ This bill also serves as a follow-up to another bill proposed by Boyer that sought to make it illegal to "publicly incite extreme thinness."70 The "thinness bill," which would have applied to advertisers and the media, actually passed the lower house of Parliament in 2008. ${ }^{71}$

These two bills, along with the rather detailed regulations for cosmetic products under the ARPP standards, suggest a commitment in France to regulate advertising, particularly in the beauty and fashion industries, to protect the public welfare. Like the United Kingdom, the French self-regulatory system works with legislators and consumers to develop a strong process for holding advertisers accountable for the claims they make in their advertisements and the effects that such claims might have on consumers.

\section{Regulation of Advertising in the United States}

The United States, like the United Kingdom and France, has a selfregulatory body known as the Advertising Self-Regulatory Council (ASRC), which establishes the regulation policies of the U.S. advertising industry and enforces them through adjudicative bodies such as the National Advertising Division (NAD). ${ }^{72}$ Compliance with NAD recommendations, however, is voluntary, and the system acts more like an alternative dispute resolution system between competing advertisers than a true regulatory body. ${ }^{73}$ True regulation of the advertising industry is left to the government, through the Federal Trade Commission (FTC) and legislation. This means that advertising regulation in the United States is ultimately beholden to the First Amendment protection of free speech. The government's ability to

69. Id.

70. Haroon Siddique, French Fight Anorexia on the Fashion Pages, GUARDIAN (Apr. 15, 2008, 9:26 AM), http://www.guardian.co.uk/world/2008/apr/15/france.fashion? INTCMP=ILCNETTXT3487.

71. Id.

72. See generally ADVERTISING SELF-REGULATORY COUNCIL, http://www.asrcreviews.org/ (last visited Apr. 22, 2014) (describing ASRC operations and history).

73. See AdVertising Self-Regulatory Council, The Advertising Industry's Process of Voluntary Self-Regulation: Policies and Procedures by the ADVERTISING SELF-REGULATORY COUNCIL 2 (2012), available at http://www.asrcreviews.org/wp-content/uploads/2012/10/NAD-CARU-NARB-ProceduresUpdated-10-9-12.pdf (discussing the adjudicative procedures of the ASRC enforcement bodies); Seth Stevenson, How New is "New"? How Improved is "Improved"?, SLATE (July $13,2009,6: 55$ AM), http://www.slate.com/articles/business/ad_report_card/2009/07/ how_new_is_new_how_improved_is_improved.html (discussing the role of NAD in advertising regulation and how competitors are more likely to notice false claims than consumers). 
regulate advertising must adhere to the common law commercial free speech doctrine.

\section{The Commercial Free Speech Doctrine Under the Central Hudson Test}

In Va. State Bd. of Pharmacy v. Va. Citizens Consumer Council, Inc., the U.S. Supreme Court extended free speech protection to commercial speech (advertising) as a means of advancing the flow of information to consumers concerning the products they buy. ${ }^{74}$ In Cent. Hudson Gas \& Elec. Corp. v. Pub. Serv. Comm'n of N.Y., the Court established a four-part test for dealing with regulations under the commercial free speech doctrine..$^{75}$ First, the communication must not be unlawful or "more likely to deceive the public than to inform it."76 The government may freely regulate any speech that is unlawful or misleading, as such speech is not protected by the First Amendment. ${ }^{77}$ When the communication is not unlawful or misleading, the state must provide "a substantial interest to be achieved by restrictions on commercial speech."78 Furthermore, the regulation must be in proportion to that interest. ${ }^{79}$ If the government can show such an interest, then the third prong of the test requires that "the restriction must directly advance the state interest involved." ${ }^{00}$ Finally, the Court must determine whether a more narrow or limited restriction on the commercial speech would be possible. ${ }^{81}$

In Central Hudson, the regulation by the Commission ordered electric utilities in New York to stop all advertising that promoted the use of electricity. ${ }^{82}$ The Court held that this was a First Amendment violation because the advertisements were not misleading in any way and the state's interests in energy conservation and protection of the pricing structure could be achieved through less restrictive means than a complete ban. 83

74. See Va. State Bd. of Pharmacy v. Va. Citizens Consumer Council, Inc., 425 U.S. 748, 769.70 (1976).

75. Cent. Hudson Gas \& Elec. Corp. v. Pub. Serv. Comm'n of N.Y., 447 U.S. 557, 566 (1980).

76. Id. at 563.

77. Id. at 563-64.

78. Id. at 564 .

79. $I d$.

80. Id.

81. Id.

82. Id. at 559.

83. Id. at 567-70. 
Since the Central Hudson decision, the Court has gone back and forth on how much deference to give the government in regulating commercial speech. In Posadas de P.R. Assoc. v. Tourism Co. of P.R., the Court upheld a ban by the Puerto Rican government on casino advertising targeting Puerto Rican residents, even though the promoted activity, gambling, was legal. ${ }^{84}$ The Court believed the state's interest in decreasing the demand for gambling by Puerto Ricans was substantial and the method of regulation was reasonable. ${ }^{85}$ Because the regulation was aimed only at Puerto Rican residents, and not tourists, the Court found the regulation to be narrowly tailored enough to meet the Central Hudson test. ${ }^{86}$ Later decisions by the Court returned to greater protection for commercial speech. ${ }^{87}$ In the 2002 decision Thompson $v . W$. States Med. Ctr., the Court found unconstitutional a statute that banned advertising on certain "compounded drugs" because there was a less restrictive alternative to achieve the government's interest. ${ }^{88}$ The Court reiterated that a government interest "in preventing the dissemination of truthful commercial information in order to prevent ... the public from making bad decisions with the information" was not sufficient under the Central Hudson test. ${ }^{89}$

The Court's recent trend has been one toward more skepticism of regulation of commercial free speech, particularly regulations made for paternalistic reasons. ${ }^{90}$ Decisions such as Thompson show the Court's commitment to protecting commercial speech. They also suggest that the Court might be moving away from Central Hudson's intermediate scrutiny approach and toward strict scrutiny for restrictions on commercial speech. ${ }^{91}$ Of course, none of this applies to advertising that

84. Posadas de P.R Assocs. v. Tourism Co. of P.R., 478 U.S. 328, 344 (1986).

85. Id. at $341-42$.

86. Id. at 343 .

87. See, e.g., 44 Liquormart, Inc. v. Rhode Island, 517 U.S. 484, 503 (1996) (striking down a ban on alcohol price advertisements and suggesting that the Court should be "skeptical of regulations that seek to keep people in the dark for . . their own good"); Edenfield v. Fane, 507 U.S. 761, 770-71 (1993) (holding that the state's burden of showing a substantial interest for the regulation "is not satisfied by mere speculation" and that the government must show a real harm that the regulation seeks to rectify).

88. Thompson v. W. States Med. Ctr., 535 U.S. 357, 370-77 (2002).

89. Id. at 374 .

90. See, e.g., John M.A. DiPippa, Regulating Food Advertisements: Some First Amendment Issues, 28 U. ARK. LITTLE RocK L. REv. 413, 417-18 (2006) (discussing the Court's shifting treatment of the commercial free speech doctrine); Ashutosh Bhagwat, $A$ Brief History of the Commercial Speech Doctrine (With Some Implications for Tobacco Regulation), 2 HASTINGS SCI. \& TECH. L.J. 103, 110-11 (2010) (suggesting that the Court may be moving towards abandonment of the Central Hudson test in favor of full protection of commercial speech).

91. Bhagwat, supra note 90 , at 111. 
is deemed illegal or misleading, but the strong protection afforded to commercial speech under the commercial free speech doctrine may make regulators and the courts more hesitant to label an advertisement as misleading.

\section{Regulation by the Federal Trade Commission}

The Federal Trade Commission (FTC) is responsible for government regulation of advertising and marketing. The FTC receives its enforcement authority from the Federal Trade Commission Act, which gives the FTC the authority to prevent unfair competition and deceptive practices that affect commerce. ${ }^{92}$ Section 52 of the Act makes it unlawful to "disseminate ... any false advertisement" for a service or product, including cosmetics. ${ }^{93}$ False advertisements are those that are "misleading in a material respect," either by the "representations made or suggested" or by the failure to reveal material facts about the product. ${ }^{94}$

The FTC focuses most of its attention on misleading claims of objective fact, not on subjective claims of puffery (things like "best" or "feels and looks great"). ${ }^{95}$ Puffery usually comes in the form of claims that reasonable consumers would not actually take literally. ${ }^{96}$ Distinguishing between puffery and objective claims is not always easy and often requires a case-by-case determination, which is how the FTC manages its regulation of advertising. ${ }^{97}$ If a claim in an advertisement is an objective fact, then the FTC employs a "reasonable basis" standard of substantiation for those claims. ${ }^{98}$ This standard requires advertisers to have a "reasonable basis" for believing the claims in their advertisements are true.99 The amount of substantiation necessary will depend on the type of product, the claim made, and the potential harm caused by misleading claims. ${ }^{100}$ Claims made in advertisements for

92. 15 U.S.C. $\$ 45(\mathrm{a})(2)(2012)$.

93. 15 U.S.C. $\$ 52(a)$.

94. 15 U.S.C. $\$ 55(a)(1)$.

95. Mary L. Azcuenaga, Comm'r, Fed. Trade Comm'n, Address at the Turkish Association of Advertising Agencies Conference on Advertising for Economy and Democracy: The Role of Advertising and Advertising Regulation in the Free Market (Apr. 8, 1997), available at http://www.ftc.gov/speeches/azcuenaga/turkey97.htm.

96. Kerry C. Donovan, Note, Vanity Fare: The Cost, Controversy, and Art of Fashion Advertisement Retouching, 26 NOTRE DAME J.L. ETHICS \& PUB. POL'Y 581, 610-11 (2012).

97. See id. at 611 .

98. Azcuenaga, supra note 95 (discussing the reasonable basis doctrine established in the 1972 FTC decision Pfizer, Inc., 81 F.T.C. 23 (1972)).

99. Id.

100. Id. 
beauty-related cosmetics sit right at the heart of the divide between puffery and objective claims. As cosmetic advertisements increasingly come to rely on claims such as "scientifically proven" and "quantifiable results," they move toward objective claims that require substantiation.

Advertising regulation in the United States has increased over time, but the FTC's continued focus is on developing a balance that "preserve[s] the valuable information content of advertisements yet limit[s] misleading impressions from being conveyed."101 This balance must be maintained while protecting free commercial speech. Over time, the Supreme Court has gone back and forth on the amount of protection to afford commercial speech, but the recent trend has increased scrutiny for regulation of such speech. The commercial free speech doctrine may make it more difficult to regulate advertising in the beauty and fashion industries.

\section{The Growing Regulation Trend}

Following in the United Kingdom and France's footsteps, other countries such as Brazil have also proposed warning label legislation. ${ }^{102}$ Australian magazines have promised to avoid large amounts of digital photograph modification. ${ }^{103}$ In 2013, a "Photoshop law" took effect in Israel that requires notice of all computer-enhanced aspects in advertising. ${ }^{104}$ The law also requires fashion models to have a bodymass index of at least 18.5.105

The effects of the media, including advertising, on body image, selfesteem, and mental and physical health have become a growing concern around the globe. As the rest of the world attempts to curb misleading and unrealistic advertising in the beauty and fashion industry, it will be interesting to see the path that the United States chooses to take. In her article discussing the current legal landscape on retouching in fashion advertising, Kerry Donovan makes the argument that warning labels, like those proposed in the United Kingdom and France, could pass muster under the current commercial free speech doctrine. ${ }^{106}$ In 2014 , U.S. lawmakers took perhaps a first step toward stricter regulation of

101. Id.

102. Donovan, supra note 96 , at 586.

103. U.K.: Curb Airbrushed Images, Keep Bodies Real, CBSNEws (Sept. 20, 2010, 2:33 PM), http://www.cbsnews.com/stories/2010/09/20/world/main6884884.shtml.

104. Bruno Nota, Israeli Law Bans Skinny, BMI-Challenged Models, ABC NEws (Jan. 3, 2013), http://abcnews.go.com/International/israeli-law-bans-skinny-bmi-challengedmodels/story?id=18116291.

105. Id.

106. See Donovan, supra note 96, at 619. 
digitally altered advertising when two members of the House of Representatives introduced a bill that would require the FTC to report to Congress on advertising that uses digital manipulation to alter the physical characteristics of the models and propose strategies to reduce such practices. ${ }^{107}$ The bill has not made it out of committee and would not actually make any changes to regulatory policy, but its proposal suggests that the problem is now on the radar or U.S. lawmakers. While the United States may eventually decide to follow the increasingly global trend toward stricter regulation of altered advertisements, its current focus, for the time being, continues to be on protecting the rights of advertisers to sell their products and for consumers to receive freeflowing information about those products.

\section{BEAUTY AND FASHION ADVERTISING BANS}

Because of the heavier regulation of advertising in the United Kingdom and France, beauty and fashion advertisements are subject to more scrutiny. This scrutiny has resulted in the banning of several advertisements from high profile cosmetic companies for misleading or unrealistic content. Consistent with recent attempts in these countries to require warning labels for digitally altered images, the banning of cosmetic and beauty advertisements seems to have increased in recent years.

In the fall of 2012, the ASA in the United Kingdom banned a Christian Dior mascara advertisement featuring Natalie Portman because her eyelashes had been digitally altered to make them appear longer and thicker. ${ }^{108}$ The advertisement claimed that the mascara produced a "spectacular volume-multiplying effect, lash by lash." 109 The ASA banned the advertisement for exaggerating the effects of the mascara, which was misleading to consumers because there was insufficient evidence to suggest the product could actually produce eyelashes like those of Portman in the advertisement. 110

The advertisement was brought to the ASA's attention by L'Oreal, a cosmetic company that previously had been targeted by the ASA for advertising violations. In early 2012, a L'Oréal ad for anti-wrinkle cream featuring actress Rachel Weisz was banned by the ASA for substantially altering the actress's complexion in a way that was

107. Truth in Advertising Act of 2014, H.R. 4341, 113th Cong. (2014).

108. Mark Sweney, Christian Dior Mascara Ad Banned for Airbrushing Natalie Portman Eyelashes, GUARDIAN (Oct. 23, 2012), http://www.guardian.co.uk/media/2012/ oct/24/dior-mascara-natalie-portman-ad-ban.

109. Id.

110. Id. 
misleading and an exaggeration of the product's possible results. ${ }^{111}$ In 2011, ads for L'Oréal-owned Lancôme brand and Maybelline brand foundations featuring Julia Roberts and Christy Turlington, respectively, were also banned by the ASA for similarly misleading consumers about the possible results of the product because of the digital enhancements to the skin of both women.112 During the investigation of the advertisements, the ASA was not permitted to see the pre-production photographs of Roberts, which led the ASA to conclude that they did not have enough evidence to fully evaluate the impact of the modifications on the photographs. ${ }^{113}$ MP Jo Swinson, who has led the charge against digitally altered advertising, brought the L'Oréal advertisements to the ASA's attention. She remarked that the concern over releasing an unaltered photograph to the regulatory agency "shows just how ridiculous thing have become."114

Beyond the context of digitally altered advertising, the ASA has also focused on sexually provocative advertising in the beauty and fashion industry. In 2011, the ASA banned a Marc Jacobs perfume advertisement with young actress Dakota Fanning because of the sexually provocative pose in the advertisement. 115 The ad had Fanning, seventeen at the time, sitting on the floor holding a large, flower-shaped bottle of perfume between her upper thighs.116 The ASA found the advertisement inappropriate because the placement of the bottle "drew attention to [Fanning's] sexuality," and her youthful appearance suggested the sexualization of a child.117 American Apparel, a U.S.based company, has come under scrutiny from the ASA multiple times for the sexualization of young models. In 2012, a series of eight advertisements by the clothing company contained photos of female models in various states of undress, some even topless. ${ }^{118}$ The advertisements ran on the company's website and used unaltered

111. John Plunkett, L'Oréal Advert Featuring Rachel Weisz Banned for Being 'Misleading,' GUARDIAN (Jan. 31, 2012), http://www.guardian.co.uk/media/2012/feb/01/ loreal-advert-rachel-weisz-banned?INTCMP=SRCH.

112. Mark Sweney, L'Oréal's Julia Roberts and Christy Turlington Ad Campaigns Banned, GUARDLAN (July 26, 2011), http://www.guardian.co.uk/media/2011/jul/27/lorealjulia-roberts-ad-banned.

113. Id.

114. Id.

115. Olivia Bergin, Dakota Fanning's Oh, Lola! Advert for Marc Jacobs is Banned, TELEGRAPH (Nov. 9, 2011), http://fashion.telegraph.co.uk/news-features/TMG8876913/ Dakota-Fannings-Oh-Lola-advert-for-Marc-Jacobs-is-banned.html.

116. Id.

117. Id.

118. Mark Sweney, 'Gratuitous' American Apparel Ads Banned, GuARDIAN (Apr. 4, 2012, 5:09 AM), http://www.guardian.co.uk/media/2012/apr/04/american-apparel-adsbanned-advertising-watchdog. 
photos, mostly of nonprofessional models. ${ }^{119}$ The ASA banned all but one of the advertisements for being exploitative, particularly in light of their "voyeuristic and amateurish quality."120

The banning of cosmetic surgery advertising has also become a hotly debated topic. As part of a scheme to regulate cosmetic surgery, the French Parliament banned all publicity and advertising of cosmetic surgery in 2005.121 The British Association of Aesthetic and Plastic Surgeons (BAAPS) has called for a similar ban in the United Kingdom. ${ }^{122}$ BAAPS believes that cosmetic surgery advertisements trivialize cosmetic surgery. ${ }^{123}$ The call for the ban came in the wake of a survey on the emotional impact of breast implants, which showed disturbing levels of emotional distress among female implant recipients. ${ }^{124}$

The United States has been more hesitant to regulate the beauty and fashion industries, as exemplified by NAD's 2010 decision on a Maybelline advertisement similar to the Turlington advertisement that was banned by the ASA in the United Kingdom. The ad for anti-aging makeup was challenged for being misleading about the ability of the product to completely remove aging imperfections. ${ }^{125}$ Even though the advertisement was altered, NAD agreed to let the advertisement be used with a disclaimer. ${ }^{126}$

In late 2011, the American regulatory body NAD took its first major step toward heavier regulation for digitally altered photos in U.S. advertisements. Seeing the trend in the United Kingdom and France, Proctor and Gamble, on a recommendation from NAD, decided to discontinue a mascara advertisement for the company's CoverGirl cosmetic brand because of digital enhancements used to make the

119. Id.

120. Id.

121. See Alain Fogli, France Sets Standards for Practice of Aesthetic Surgery, 15 CLINICAL RISK 224, 225 (2009) (discussing French Decree 2005-776, which banned all publicity and advertising of cosmetic surgery).

122. Sarah Boseley, Cosmetic Surgery Advertising Ban Urged By Leading Surgeons, GUARDIAN (Jan. 22, 2012, 1:31 PM), http://www.guardian.co.uk/lifeandstyle/2012/jan/22/ ban-advertising-cosmetic-surgery.

123. Id.

124. Id. The survey used women who had been involved in the 2010 scandal involving faulty breast implants. See Kristen Hallam, Breast Implant Scandal Spurs U.K. Cosmetic Surgery Review, BLOOMBERG (Aug. 15, 2012, 11:11 AM), http://www.bloomberg.com/ news/2012-08-14/breast-implant-scandal-spurs-u-k-cosmetic-surgery-review.html.

125. See Cassandra A. Soltis, Cosmetic Advertisement + Photoshop = Deceptive Advertising?, FDA L. BLOG (Aug. 4, 2011, 7:48 PM), http://www.fdalawblog.net/ fda_law_blog_hyman_phelps/2011/08/cosmetic-advertisement-photoshop-deceptiveadvertising-.html.

126. Id. 
eyelashes thicker. ${ }^{127} \mathrm{NAD}$ claimed that it was aware of the need to be more vigilant about the use of Photoshop in cosmetic advertisements "where there is a clear exaggeration of potential product benefits."128 Since this decision by NAD, however, little more has been done to curb the use of such practices in advertising. In an $\mathrm{ABC}$ News report following the ASA ban on the Portman Dior mascara advertisement in 2012, AdWeek's managing editor Lisa Granatstein argued that photoshopping and digital enhancement in advertising is a routine practice in U.S. advertising and companies are hesitant to point fingers at each other for such practices. ${ }^{129}$ Granatstein admits, "[i]t's freedom of speech here in the United States and it's really an excuse for anything from deceptive campaign advertising to mascara advertising."130

While European countries such as the United Kingdom and France have increasingly sought to regulate beauty and fashion advertising, including the banning of advertisements found to be misleading, the United States has been slower to follow suit. The strong presence of watchdogs such as the ASA in the United Kingdom has fostered an advertising culture that is more accustomed to regulation, so businesses are more proactive about bringing misleading advertising practices of their competitors to the attention of regulators. In contrast, the cultural importance of free speech in the United States has made businesses, and likely consumers, more gun-shy about calling attention to such practices. Recent attempts to increase regulation of advertising in the United States, including such practices as digital enhancement, may suggest that U.S. regulators are ready to follow in the footsteps of their European counterparts; but the continued overwhelming presence of digitally enhanced photos in advertising suggests that it will be a slow change.

\section{WHY U.S. ADVERTISERS SHOULD TAKE No'TICE OF GLOBAL REGULATION TRENDS}

Businesses spend billions of dollars each year in advertising their products, both domestically and internationally. As world markets expand globally, the market for consumers expands with them. U.S.

127. Jim Edwards, US Moves Toward Banning Photoshop in Cosmetics Ads, Bus. INSIDER (Dec. 16, 2011, 8:00 AM), http://articles.businessinsider.com/2011-12-16/news/ 30523807_1_nad-advertising-standards-authority-misleading-ads.

128. Id.

129. See Suzan Clarke, Agency Bans Dior Mascara Ad Featuring Natalie Portman, ABC NEws (Oct. 25, 2012, 8:45 AM), http://gma.yahoo.com/blogs/abc-blogs/agency-bans-diormascara-ad-featuring-natalie-portman-124547129--abc-news-fashion-and-beauty.html.

130. Id. 
companies spend more than $\$ 100$ billion each year on global advertising. ${ }^{131}$ Because so much money is spent on advertising in foreign markets, U.S. advertisers must be aware of the cultural and legal trends in those markets, including the state of advertising regulation. Regardless of what the U.S. government and self-regulating watchdogs like NAD decide to do about regulation of advertising, advertisers themselves need to consider what is happening abroad in the advertising industry.

The global economy and high levels of international trade have led to questions about the homogenization of the world's cultures. The homogenization theory of globalization posits that global consumerism is leading to the Westernization and, in particular, the Americanization of cultures around the globe. ${ }^{132}$ It suggests that the standard images and messages in advertising from leading global brands like Coca-Cola and the U.S. media attempt to sell global consumers American ideals of personal success and gratification. ${ }^{133}$ The rest of the world, however, is pushing back. I argue that the success of U.S. companies in selling this lifestyle through advertising is constrained by increasing regulation of advertising around the world. The growing trend toward variation in marketing strategies to meet the demands of local cultures is evidence of the backlash against cultural homogenization. ${ }^{134}$ This development of "locally sensitive niche marketing" known as "glocalization" is quickly becoming the dominant global advertising strategy. ${ }^{135}$ U.S. companies will need to continue to "glocalize" their marketing strategies if they hope to compete in global markets. Any glocalization strategy must include sensitivity to foreign advertising regulation.

One of the major challenges of marketing products in foreign markets is breaching the language and cultural barrier to reach target consumers with the advertising message. Advertisers must adapt their products and their advertising messages to the needs and desires of

131. Osama Zain, Challenges of the Foreign Market: Advertising and Promotions, ARTICLES TODAY (June 19, 2012), http://articles2day.org/2012/06/challenges-of-the-foreignmarket-advertising-and-promotions.html.

132. Robert Holton, Globalization's Cultural Consequences, 570 ANNALS AM. ACAD. POL. \& SOC. SCI. 140, 142 (2000). The homogenization theory is the most widely held belief about the effects of globalization on culture. Id. The theory has been criticized, however, for oversimplifying the processes and phenomena that accompany globalization. See id. at 143. Globalization of culture often involves an infusion of foreign goods and ideas followed by resistance or modification of those goods and ideas to meet the needs of the local population. Id.

133. See id. at 142 .

134. See id. at 144 .

135. Id. 
global consumers. ${ }^{136}$ A considerable aspect of this adaptation is understanding how foreign consumers feel about the advertisements to which they are exposed. Global advertising in the beauty and fashion industries presents a unique challenge because these industries are built on ever-changing beliefs about style and what it means to be beautiful. The prevailing theory in beauty and fashion advertising has been to project an idealized version of beauty with ultra-thin models and perfect skin. While that theory still dominates the way advertisers in the industry market their products to consumers around the globe, the recent increase in regulation of advertising suggests that both consumers and regulators alike have become more attuned to the deceptive practices of beauty and fashion advertisers.

American consumers by and large accept advertising as a necessary function of commercial society and have shown ambivalence about the practices of advertisers. ${ }^{137}$ This ambivalence, combined with the staunch defense of free speech in the United States, even in the commercial context, has meant a hesitance, on the part of consumers and competitors, to point out deceptive advertising practices and, on the part of regulators, to curb such practices. ${ }^{138}$ In contrast, advertisement regulation through the ASA in the United Kingdom has been much more prevalent. ${ }^{139}$ A large part of the increasing regulation of advertising in the United Kingdom has resulted from the consumer culture. Consumer interest organizations have a strong presence in the media and in the advertising self-regulatory system. ${ }^{140}$ British consumers have taken an active role in advertising regulation, especially in relation to the depictions of women in advertisements. ${ }^{141} \mathrm{~A}$ similarly strong network of consumer organizations exists in France. ${ }^{142}$ Consumers in both Britain and France are aware of and accept the regulatory practices in their countries. ${ }^{143}$

Such a cultural contrast must be taken into account by U.S. companies hoping to market their clothing and cosmetic products to foreign consumers. The greater skepticism by British and French

136. See id.

137. See Boddewyn, supra note 53, at 3, 135. See also PotTER, supra note 1. Potter reports that $45 \%$ of Americans have a favorable attitude towards advertising. Id. at 221 . Only $15 \%$ have a negative attitude about it. Id. Furthermore, Americans generally are not consciously aware of the amount of advertising they are exposed to and how it shapes their behaviors. See id.

138. See BoDDEWYN, supra note 53, at 3,5.

139. See id. at 3.

140. Id. at 128 .

141. Id. at 129 .

142. See id. at 53.

143. Id. at 11 . 
consumers of the techniques used by advertisers is likely to make them less tolerant of advertisements, and thus less susceptible to the messages in those advertisements. If U.S. advertisers cannot effectively convey their message to consumers through advertising they lose revenue. When billions of dollars are at stake, U.S. companies cannot afford to ignore foreign consumers.

i:

It is not just consumers that U.S. advertisers must worry about. Because the British and French media participate in the self-regulatory schemes, the ability of U.S. advertisers to even reach foreign consumers depends on getting their advertisements into foreign magazines, on foreign television stations, and on foreign websites. ${ }^{144}$ Advertisers can only reach these advertising platforms if their advertisements conform to the British and French advertising codes. Without access to foreign media channels, U.S. advertisers must use direct lines to consumers such as the mail, but in foreign markets, direct access to consumers is more limited. ${ }^{145}$ If U.S. advertisers fail to meet international standards, their advertisements are likely to be banned, as has happened repeatedly to American Apparel, a U.S.-based clothing company.

Banned advertisements cost U.S. companies more than just the price of making the advertisement. Banned advertisements attract negative attention to the product and the brand. ${ }^{146}$ Aside from published decisions by foreign regulators, news organizations often report advertising bans, particularly if the advertisements are from high profile brands. ${ }^{147}$ The Advertising Code in the United Kingdom relies on this adverse publicity to maintain its self-regulatory system. Such negative publicity can affect the opinion of consumers, both domestically and internationally, about the integrity of the brand.

The negative consequences for U.S. advertisers of continuing to adhere to U.S. conceptions of commercial free speech when marketing their products overseas are clear. The use of misleading and deceptive advertising practices in beauty and fashion advertisements may cost billions of dollars in lost revenue, consumers, and brand prestige in foreign markets. As other countries place more scrutiny on these misleading practices, U.S. advertisers must conform their practices to new global standards of acceptable advertising. The global economy demands an advertising industry that is accountable, diverse, and increasingly local. U.S. advertisers must meet this challenge head on and not wait for U.S. regulatory bodies to catch up with their foreign counterparts.

\footnotetext{
144. See id.

145. See iu. at 6.

146. COinit. OF ADVER. PRACTICE, supra note 10, at 104.

147. See id.
} 


\section{CONCLUSION}

Advertising is an important part of commercial business. It gives companies a way to gain awareness for their products and consumers vital information about what they buy. U.S. companies spend billions of dollars on advertising each year, both domestically and internationally. Consumers are flooded with advertisements on a daily basis. The prevalence of advertising in today's world means that governments and advocacy groups pay special attention to the content in those advertisements and the messages that this content sends to consumers. Regulation of the advertising industry has become an ever-increasing function of both governments and private organizations. Advertising in the beauty and fashion industries has recently been highlighted as a major focus of regulators in countries around the globe.

Because of the global nature of today's economy and the financial stakes involved in the advertising business, U.S. companies must remain aware of these trends in advertising regulation. Advertising regulation across Europe has recently targeted the beauty and fashion industries for misleading practices, which include the use of digital modification software and unrealistic claims about the results of cosmetic products. Countries such as the United Kingdom and France have been leading this charge, both through their self-regulatory bodies in the industry and through legislation. So far the United States has been more hesitant to impose similar regulations because of its strong commitment to free speech, even in the commercial realm.

Regardless of what the U.S. government decides to do about regulating these practices in the advertising industry, the global economy demands that U.S. companies within the beauty and fashion industries adjust their practices to conform to world trends. The economic stakes involved are too high for U.S. advertisers to ignore the warnings sent by the ASA and ARPP. If U.S. companies intend to market and sell their products overseas, then the standards of foreign regulators, competitors, and consumers must be forefront in their minds because they will not receive the same level of deference as they are given domestically. If international pressure helps to curb some of the more deceptive practices used by U.S. advertisers within the beauty and fashion industries, the need for regulators to legislate the issue may not be so pressing. 
